\title{
Revisiting the Concept of Diagonal Pre-cure Splitting of Horizontal Increments in Direct Composite Restorations
}

\author{
Khamis A Hassan ${ }^{*}$ Salwa E Khier ${ }^{2}$ \\ ${ }^{1}$ Professor and Senior Clinical Consultant of Operative Dentistry, Global Dental Center, Vancouver, BC, \\ Canada \\ ${ }^{2}$ Professor of Dental Biomaterials, Global Dental Center, Vancouver, BC, Canada \\ *Corresponding Author: Khamis Hassan, Professor and Senior Clinical Consultant of Operative Dentistry, \\ Global Dental Center, Vancouver, BC, Canada; Email: globaldental@shaw.ca \\ Received Date: 07-05-2020; Accepted Date: 20-05-2020; Published Date: 27-05-2020 \\ Copyright $^{\circledR} 2020$ by Hassan K, et al. All rights reserved. This is an open access article distributed under the terms \\ of the Creative Commons Attribution License, which permits unrestricted use, distribution, and reproduction in \\ any medium, provided the original author and source are credited.
}

\begin{abstract}
The unavoidable, inherent property of polymerization shrinkage in composite resins generates stresses in direct composite restorations which are detrimental to composite material, prepared tooth structure and interfacial bond. Several restorative techniques have been advocated to minimize these stresses and increase the restoration success rate. One such technique is the split-increment technique which is based on the concept of diagonal pre-cure splitting of horizontal increments for the relief of shrinkage stresses by creating contraction joints in each composite increment prior to light curing. This mini review aims to revisit this concept for enhancing its understanding and providing more concise guidelines for its application in moderate-to-large cavities in the cervical, occlusal, and proximal areas.
\end{abstract}

\section{Keywords}

Split-increment; Pre-cure; Diagonal cut; Horizontal placement techniques; Composite Polymerization shrinkage; Contraction joint; Stress reduction; C-factor; Cervical; Occlusal; Proximal

\section{Introduction}

In recent years, the topic of direct placement of composite resins has come to the forefront in restorative dentistry. Polymerization shrinkage in dental composites is recognized as a 
significant material limitation that substantially complicates the placement of composite restorations [1-3].

Shrinkage creates stresses within composite resin and its interface with bonded cavity walls $[1,2]$. These stresses lead to one of the following: adhesive failure at composite-tooth interface resulting in marginal straining and secondary caries, cohesive failure in the form of microcracks in composite resin, or cusp deformation. This deformation leads to propagation of existing enamel microcracks resulting in postoperative sensitivity [1,2].

The pre-cure split-increment placement technique of composite resins advocates using diagonal cuts in each horizontal composite increment made using a blunt flat plastic instrument in push stroke for splitting each increment prior to light curing into four triangular segments [4-6]. These are considered as pre-cure contraction joints intended for creating free, unbonded composite surfaces [4,5]. These surfaces are intended to allow for resin flow or plastic deformation during polymerization which directs the shrinking resin towards such surfaces and away from bonded cavity walls [4,6,7].

This technique utilizes two diagonal cuts in each horizontal composite increment when restoring occlusal and cervical prepared cavities, however, a single cut is used when restoring the proximal box because of the small increment size [4-7].

Pre-cure splitting of each composite increment into four triangular segments results in reduction of the $\mathrm{C}$-factor from the ratio of 5.0 to approximately 0.5 and hence the reduction of the generated shrinkage stresses [4,5]. This technique produces a more naturally looking restoration by using flat composite dentin and enamel increments of uniform thickness which closely resemble the arrangement of natural tooth structure.

Clinicians understand that placing a high-quality direct posterior composite resin restoration is technique sensitive and demanding [4]. In the split-increment technique, the clinicians need to sculpt only the last dentin increment and the enamel increment overlying it [4]. By comparison, the successive cusp buildup technique requires clinicians to place and sculpt several wedgeshaped oblique increments for building up each cusp separately [4]. This would require considerably more chairside time than that needed to place a similar restoration using the splitincrement technique which probably would require dentists to increase their fees [5].

This mini review paper revisits the concept of diagonal pre-cure splitting of horizontal increments in direct composite restorations. It aims to enhance clinicians' understanding of this concept and provide more concise guidelines for its application in moderate-to-large cavities in the cervical, occlusal, and proximal areas. 


\section{Cervical Composite Resin Restoration}

A large cervical carious lesion extending onto the root surface is restored with composite resin using the pre-cure split-increment technique (Fig. 1). Two flat $1.5 \mathrm{~mm}$ thick composite resin increments are used; the number of increments depends on the prepared cavity depth [6]. The first increment is applied to cover the axial wall and split before light curing into four triangular segments with two diagonal cuts $(1.5 \mathrm{~mm}$ wide and $1.5 \mathrm{~mm}$ deep) using a small-bladed instrument and followed by light-curing [4]. The two cuts are then filled with the same dentin shade composite where one cut is filled and light cured, and the second cut is filled one half at a time and light cured [6]. The second increment is applied to fill the cavity and is treated like the first increment.

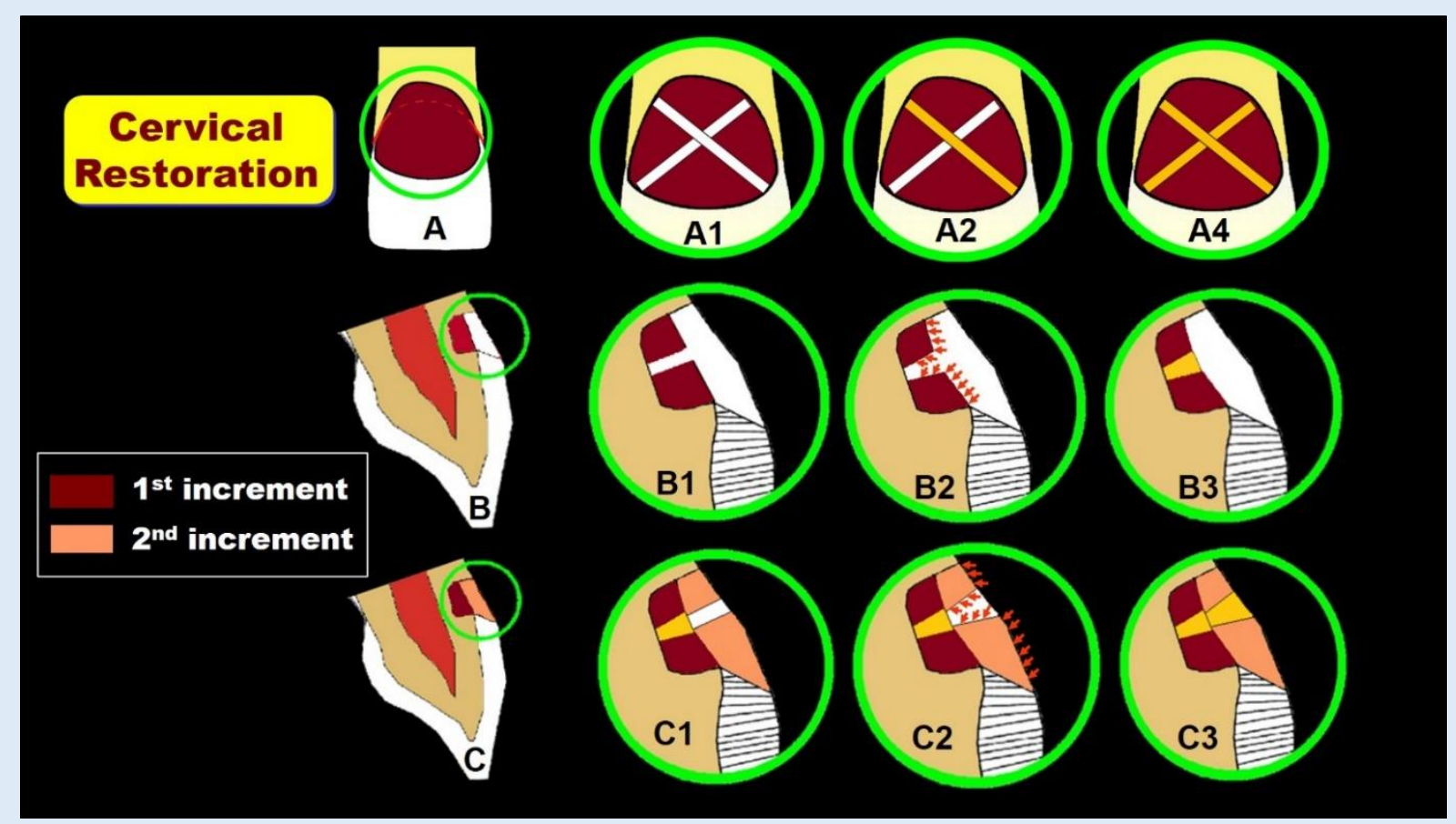

Figure 1: Step-by-step pre-cure split-increment technique for placing cervical composite restoration in anterior tooth with the cervical margin located below the CEJ (Labial aspect:

A-A4, $1^{\text {st }}$ composite increment), (Proximal aspect: B-B3, first composite increment) and (Proximal aspect: $\mathrm{C}-\mathrm{C} 3$, second composite increment).

\section{Occlusal Composite Resin Restoration}

A large occlusal lesion in a molar tooth is restored with composite resin using the pre-cure split-increment technique (Fig. 2). Three flat $1.5 \mathrm{~mm}$ thick composite resin increments are used; the number of increments is based on the prepared cavity depth [4]. Assuming that selected shade is A1, three composite dentin shades (A1, A2, and A3) are used where A3 dentin 
shade composite (with highest chroma) is applied on cavity floor as the first increment [4,5]. Prior to light-curing, two diagonal cuts are made in this increment using a small-bladed instrument and followed by light-curing. The two cuts are then treated in a way like that used for the cervical composite restoration [4,5]. The second flat increment of A2 dentin shade composite is used to cover the first increment and is treated like the first increment [4]. The third increment of A1 dentin shade composite is used to fill the cavity and is treated using the same steps of increment splitting and light-curing with exception that part of the middle area of the diagonal cuts is not filled with composite, but with pit and fissure stain for internal characterization and light cured [4]. Then, A1 enamel shade composite increment is applied to replace the lost enamel and shaped to establish the occlusal morphology and light cured $[4,5]$ The final increment of translucent shade composite is placed to cover the enamel composite increment and light cured.

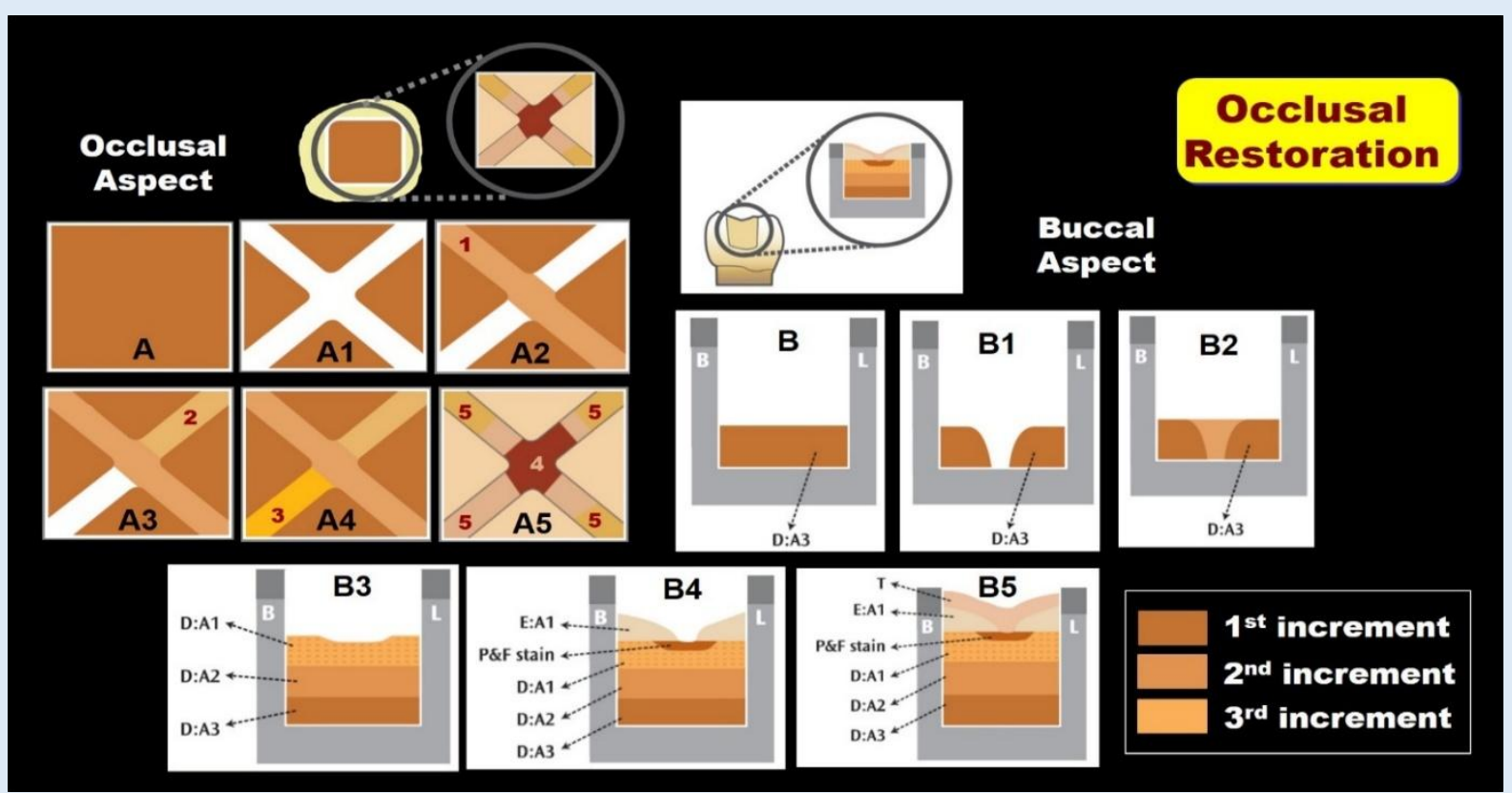

Figure 2: Step-by-step pre-cure split-increment technique for placing occlusal composite restoration (Occlusal aspect: A-A5, first composite increment), (Buccal aspect: B-B3, first composite increment) and (Buccal aspect: B3-B5, second, third, stain, enamel and translucent composite increments).

\section{Proximal Composite Resin Restoration}

Composite resin is placed in the proximal portion of a large Class II cavity in a molar tooth using the pre-cure split-increment technique (Fig. 3) [4]. The restoration proximal surface and the marginal ridge are built using an increment of A1 enamel shade composite and light cured converting Class II prepared cavity into Class I [8]. 
The first increment of A3 dentin shade composite is placed in the proximal box to cover the gingival wall, with no light curing, and received a diagonal cut splitting it into two triangular segments, and then light cured [7]. The cut is then filled with the same dentin shade composite and light cured. Although the split-increment technique advocates using two diagonal cuts in each flat composite increment, a single cut is used in the proximal box because of the small increment size [4-7]. The proximal box is filled to the level of the pulpal floor with a second increment of A2 dentin shade composite and treated like the first increment [7]. The remainder of the occlusal cavity is restored following the procedure described previously for large Class I composite resin restorations.

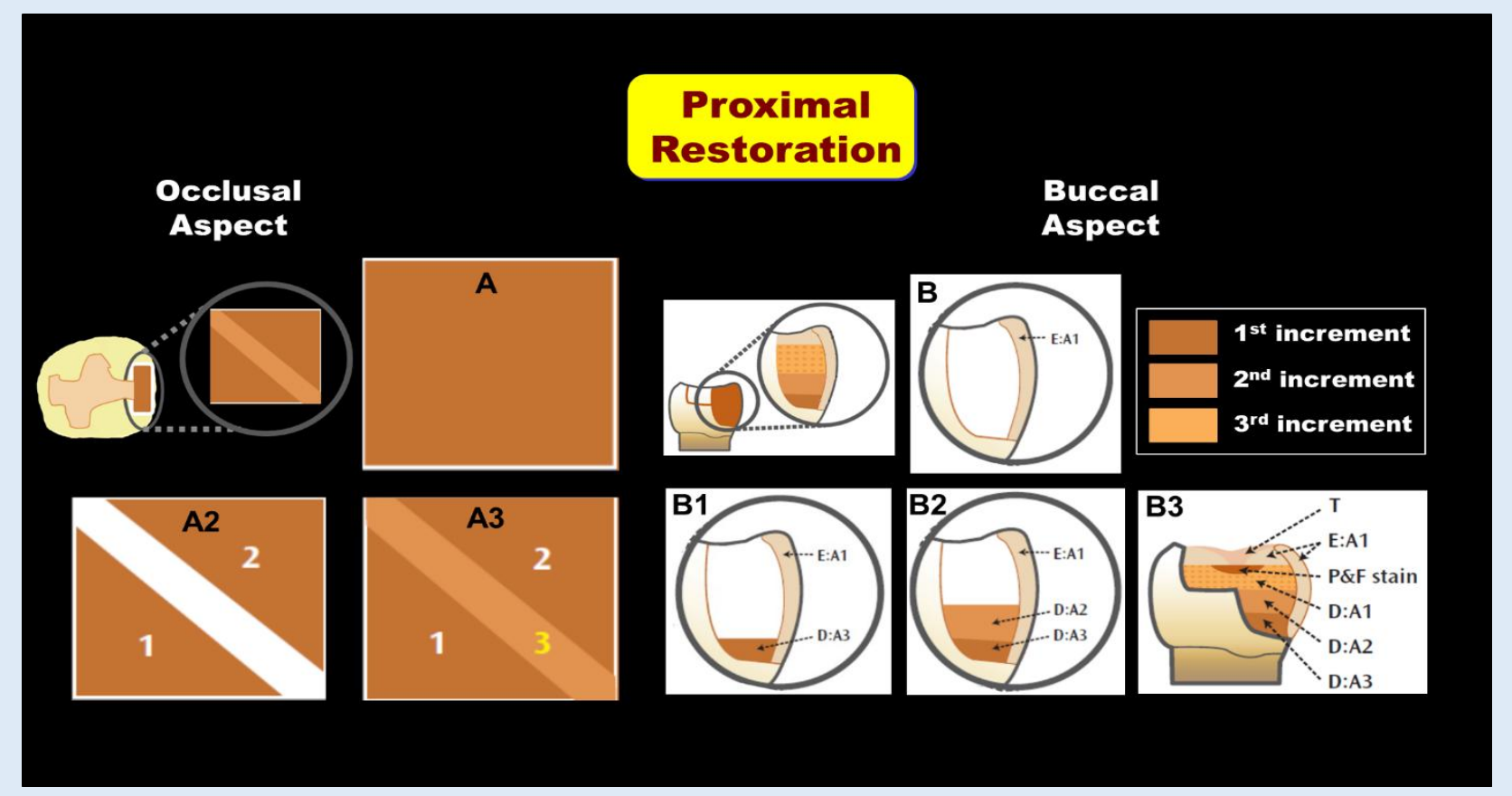

Figure 3: Step-by-step pre-cure split-increment technique for placing proximal composite restoration (Occlusal aspect: A-A3, first composite increment), (Buccal aspect: B, first composite increment), and (Buccal aspect: B1-B3, first, second, third, stain, enamel and translucent composite increments).

Several research studies reported the influence of different restorative placement techniques on microleakage associated with direct composite restorations [9]. A research study showed that the split- incremental technique significantly minimized microleakage in Class V cavities restored with silorane-based resin composite when compared with oblique layering technique [10]. Another research study concluded that the split incremental technique showed the least microleakage in Class II composite restorations at occlusal margin, followed by centripetal and oblique techniques, whereas it showed the least microleakage at gingival margin with no significant difference between centripetal and oblique techniques [11]. The efficacy of three placement techniques in marginal sealing of Class $\mathrm{V}$ composite restorations extending onto the root was compared and it was concluded that the oblique and occlusogingival incremental techniques exhibited higher degrees of microleakage at the occlusal and gingival margins, as compared to that of split-increment technique [12]. In a research study comparing the bulk

Hassan K | Volume 1; Issue 1 (2020) | JDHOR-1(1)-004 | Review Article

Citation: Hassan K, et al. Revisiting the Concept of Diagonal Pre-cure Splitting of Horizontal Increments in Direct Composite Restorations. J Dental Health Oral Res. 2020;1(1):1-6. 
insertion with six incremental techniques, it was stated that the split-increment technique and the fiber insert in gingival increment showed significantly lower microleakage at gingival margins of Class II restored with a nanocomposite resin when compared to bulk insertion, oblique, centripetal, flowable composite [13].

\section{References}

1. Davidson CL, de Gee AJ, Feilzer A. The competition between the composite-dentin bond strength and the polymerization contraction stress. J Dent Res. 1984;3:1396-9.

2. Jensen ME, Chan DCN. Polymerization shrinkage and microleakage. In: Vanherle G, Smith DC, Posterior composite resin dental restorative materials. Utrecht, The Netherlands: Peter Szulc Publishing Co.1985;243-62.

3. Lai JH, Johnson AE. Measuring polymerization shrinkage of photo-activated restorative materials by a water-filled dilatometer. Dent Mater. 1993;9(2):139-43.

4. Hassan K, Khier S: Split-increment horizontal layering: A simplified placement technique for direct posterior resin restorations. Gen Dent. 2005;53:406-9.

5. Hassan K. Polymerization shrinkage stress reduction in direct occlusal composite restoration placed using split-increment horizontal technique - case report. WebmedCentral DENTISTRY 2010;1(9):WMC00626.

6. Hassan KA, Khier SE. Split-increment technique: an alternative approach for large cervical composite resin restorations. J Contemp Dent Pract. 2007;8(2):121-8.

7. Hassan K, Khier SE: Composite resin restorations of large class ii cavities using split-increment horizontal placement technique. Gen Dent. 2006;54(3):172-7.

8. Hassan K, Mante F, List G, Dhuru V. A modified incremental filling technique for Class II composite restorations. J Prosthet Dent. 1987;58(2):153-6.

9. Hassan KA, Khier SE. A review on incremental techniques for placing direct occlusal and proximal composite restorations. Dental \& Oral Health Int J. 2019;1(1):1-11.

10. Usha HL, Kumari A, Mehta D, Kaiwar A, Jain N. Comparing microleakage and layering methods of silorane-based resin composite in Class $\mathrm{V}$ cavities using confocal microscopy: An in vitro study. $\mathrm{J}$ Conserv Dent. 2011;14(2):164-8.

11. Nadig RR, Bugalia A, Usha G, Karthik J, Raghoothama R. Effect of four different placement techniques on marginal microleakage in class ii restorations: an in vitro study. World J Dent. 2011;2:111-6.

12. Khier S, Hassan K. Efficacy of composite restorative techniques in marginal sealing of extended class v cavities. International Scholarly Research Network. (ISRN) Dentistry. 2011;80197.

13. Bugalia A, Yujvender, Bramta N, Kharbanda J, Atri M. Effect of placement techniques, flowable composite, liner and fibre inserts on marginal microleakage of Class II composite restorations. J Evidence Based Med \& Healthcare. 2015;2:4779-87. 